Revista de Antropología Social

ISSN: 1131-558X

http://dx.doi.org/10.5209/rev_RASO.2016.v25.n1.52634

\title{
Entretejimientos y urdimbres. Transiciones políticas de un concepto desgarrado donde la razón se bifurca ${ }^{1}$
}

Adriana Guzmán²

DÍAZ CRUZ, Rodrigo. 2014. Los lugares de lo político, los desplazamientos del símbolo. Poder y simbolismo en la obra de Victor W. Turner, Gedisa/UAM, México.

Éste es un libro vasto, generoso, en el que Rodrigo Díaz discute ampliamente perspectivas, autores y puntos de vista, no sin humor y en ocasiones cierta sutil ironía que, acaso, el autor disfruta. Este trabajo, dice el autor, tiene como objetivo comentar la obra de Victor Turner; aunque no es tan claro si Díaz habla de la antropología de Turner o con Turner de la antropología, como si, súbitamente, Turner se hubiese convertido en el Sandombu de Díaz revelándole algunos de los entramados de las raíces de la antropología; pues ciertamente Díaz hace extensísimas exposiciones y explicaciones de la obra de Turner pero, para ello, sigue los pasos de lo más relevante de la conformación de esta disciplina y de los puntos claves de la epistemología.

Rodrigo Díaz, seguramente con lo aprendido gracias a su informante Turner, hace etnografía de las etnografías y de las antropologías a ellas asociadas; relata la cita, la fuente, la premisa teórica, la situación académica y política del país etnografiado y del etnógrafo mismo. No es, pues, Turner quien habla a través de Díaz, sino Díaz haciendo ver el diálogo de Turner con Gluckman para observar la inviabilidad de la visión según la cual "las sociedades simples eran homogéneas y relativamente estables" (55), o para dar cuenta de que Evans-Pritchard, al estudiar a los Nuer, hizo "una etnografía tal vez demasiado perfecta para ser real" (42). Díaz, de la mano de su informante y antropólogo Turner, también revisa la antropología evolucionista o intelectualista, para romper con la construcción del yo-monológico que sólo entra en contacto con el mundo a través de las representaciones que de él tiene en el interior; así como con la idea de que es posible encontrar el verdadero significado, desconocido por cierto por los primitivos, gracias a que el antropólogo es una auctoritas que sí sabe cómo hacerlo (204-206). E igualmente da cuenta de la construcción del programa simbolista de Durkheim destacando no sólo lo que denomina la lectura sociológica

0 Título que atiende a las propuestas del autor quien señala que una "de las cosas que hacemos los antropólogos es tratar de aprender, describir, comprender entretejimientos y urdimbres: los usos de palabras y símbolos incrustados en prácticas sociales que no se despliegan en vacíos políticos y culturales, sino en situaciones particulares con maneras plurales de ver, valorar y sentir" (255). Con respecto al símbolo, el autor dice que es "un concepto desgarrado donde la razón se bifurca" (340) (en ambas citas, los resaltados son del autor). Dado que todas las citas proceden del texto comentado, solamente se señalará la paginación.

2 Escuela Nacional de Antropología e Historia (ENAH, México) ariatnamun@hotmail.com 
de las representaciones colectivas, la más conocida, sino aportando la que denomina una lectura cognitiva (que se ancla en la propuesta del propio Durkheim): es en el espíritu humano donde se encuentra el "origen simbólico de la sociedad" (224), y los símbolos no son meros artificios o etiquetas que se le añaden a las representaciones, sino que "los símbolos forman parte integral de éstas" (222).

En éstas, entre otras exploraciones, se apoya Rodrigo Díaz para ir dando cuenta de las raíces en las que se asienta no sólo la obra de Turner, sino la antropología en su conjunto: premisas que no se han revisado en su totalidad; supuestos que olvidan las dinámicas del mundo de los etnografiados y también, a veces, las del propio antropólogo; procedimientos que simplifican la sutileza, vastedad y alcances de lo político. Así, Díaz nunca olvida a Turner, pero lo lleva más allá; su punto de partida es sencillo y contundente: "no hay exilio cósmico" $(57,77)$. Por lo tanto, es indispensable integrar a los sujetos, las mentalidades y los cuerpos, comprenderlos como unidad indisoluble - no hay sujeto sin cuerpo-, y asumir que invariablemente están inmersos en relaciones de poder que no son meros discursos, sino que se encarnan y se tornan prácticas, acciones, reconfiguraciones de los individuos, los grupos, las instituciones y, en suma, la cultura en su conjunto.

Con base en estos principios, las propuestas de Díaz se encadenan bajo sustantivas premisas:

- Centrar la observación y el análisis en los procesos, es decir, los flujos, las conexiones, las interdependencias, lo cual posibilita nuevas miradas, distintos focos de atención que devendrán en el conocimiento, no sólo de las estructuras y las normas institucionalizadas, sino también de las experiencias y las maneras en las que los individuos y los grupos adecuan, o no, el pensamiento y la acción a las situaciones de vida; pues el mundo social es un constante devenir que construye procesualmente de manera constante el tiempo, el espacio y toda situación.

- Asumir que en todo tiempo y lugar es la agencia humana - y no humana-, sus cuerpos, sus impulsos y pensamientos, sus pasiones y discursos, la que da sentido a los hechos y las prácticas en adecuación, y a veces subversión, permanente con las normas y las estructuras de toda índole: "Sin agentes [...] el presente no tiene presencia" (69).

- Comprender que la sociedad no es un sistema perfectamente integrado y armonioso, un rompecabezas en el que las piezas embonan a la perfección, sino un proceso con características sistemáticas.

- Asumir que la comprensión de las configuraciones sociales no se agota en el mundo de las palabras y los discursos, sino que es menester considerar las prácticas, los impulsos, las acciones, que no tienen una significación directa o intrínseca.

- Romper con el modelo criptológico de interpretación que asume la existencia de significaciones fijadas por la tradición, y por ende intrínsecas e inamovibles, ante las que toda comprensión se reduce a un proceso mecánico de reproducción. En vinculación con ello, será menester observar que los símbolos no tienen una lectura unívoca e inalterable, ni se agotan con sus contenidos proposicionales.

- Romper con el modelo interpretativo derivado de la lectura sociológica de las representaciones colectivas de Durkheim que exige que los "nativos 
satisfagan dos requisitos: el de la ignorancia y el de la incorregibilidad de las creencias" (215).

- Romper con la trivialización conceptual de la idea de ritual.

- Revisar la manera en la que la antropología se ha construido a sí misma, pues no hay clasificación ni régimen conceptual que no esté anclado en "políticas conceptuales - la interrelación de formas de describir con juicios normativos y valorativos" (237). Toda comprensión del mundo está imbricada en dispositivos y redes de saber-poder y por lo tanto de procesos de subjetivación, a tal grado que la historia de la construcción de los saberes "puede ser pensada como la historia de las transformaciones en el orden de las cosas [...] Más todavía, los sistemas u órdenes clasificatorios quieren fijar la realidad, quieren representarla como si ella fuera estable, inmutable, resistente al tiempo, o al menos controlable por largo tiempo" (237). Son procesos de regularización que al "estabilizar e inscribir una realidad, tienen fuerza performativa, un poder normalizador que se constituye y legitima por exclusión" (237-238).

Al elaborar su propuesta, Díaz observa al mundo y para poner ejemplos es generoso: la Guerra Fría, la construcción de la figura moderna del mundo, las peripecias de los ndembu (que retoma de Turner), la revolución de Independencia en México (que también trabajara Turner); los ritos de coronación de la Francia medieval, el cuerpo grotesco medieval (relatado por Bajtin), conflictos estudiantiles, los fundamentalismos religiosos y guerras que los acompañan, etcétera. Todo ello para mostrar y sostener, con Turner, que "una antropología política que desconsidere el análisis simbólico, la lucha por la inscripción y hegemonía de los sistemas de significados y representaciones y sus efectos, es una antropología ciega; y a su vez, una antropología simbólica que omita el esclarecimiento de las relaciones de poder es una antropología vacía" (53).

Rodrigo Díaz destaca dos premisas y modos de trabajo del procesualismo: por un lado, la constante observación de la relación entre los datos, las categorías analíticas y los enunciados teóricos y, por otro, el tender puentes entre "el análisis de las estructuras, los procesos, y la agencia humana, entre la sociedad y la intención, entre la cultura y la subjetividad" (56). Es un análisis comprometido con la inscripción plural, históricamente conformada, de los poderes en los lugares y arenas políticas, poderes que se despliegan de modo estratégico de acuerdo a diversas circunstancias y modos de adecuación, individual y colectiva, a las mismas. Tarea y proceder que Díaz asume al revisar la antropología misma.

En una argumentación que avanza en espiral, Díaz retoma un planteamiento, lo enriquece con nuevas o renovadas propuestas y lo deja más jugoso que como lo encontró, para tomar otro planteamiento y en algún momento recuperar lo que ya había avanzado, y así sucesivamente. Retoma y complementa cada punto nodal de Turner: la noción de drama social -pero ahora entendido como "metáfora de raíz" o como diría el propio Turner, paradigmas de raíz (64 y ss.); esos sitios de emergencia que son matrices de experiencia, con sus procesos de regularización que cumplen una función reparadora y/o de ajuste situacional, en los que hay subconjuntos de empresas sociales, como, enriquece Díaz, la valencia diferencial de los sexos trabajada por Héritier (78). Los dramas sociales son procesos políticos (que se caracterizan por: ser públicos, referirse a metas u objetivos, e involucrar la 
existencia de conductas diferenciadas en relación con las metas (72)) o lugares de lo político, donde se observa la heterogeneidad de las formas de poder (74) para dar cuenta de las movedizas arenas que se desarrollan en campos políticos (que no son meros agregados de elementos aislados sino interdependencias espaciales y temporales que expresan su unidad operativa de tal suerte que "cada caso puede ser representado como un nexo espacio-temporal específico de los componentes del campo, y cualquier suceso en el campo ocurre en y es resultado de una totalidad de componentes sociales coexistentes como los grupos, subgrupos, miembros, canales de comunicación, barreras, etc." (130)).

Por supuesto, Díaz no olvida mencionar las fases de los dramas sociales y la existencia de los procesos primarios ("impulsos que mueven a las colectividades a eliminar compulsivamente aquello que represente un obstáculo a sus aspiraciones y deseos" (123)), pero destaca la importancia que tiene la orientación de los actores mismos (la competencia entre ellos por el control; el interés compartido o no y la voluntad de mantener o derruir un orden normativo específico (131)) que juegan con símbolos, dominantes e instrumentales (120-121); pero, agrega y enfatiza Díaz, los símbolos son utilizados porque significan y no para significar, con lo que destaca la eficacia simbólica. Al hablar de ello, el autor recupera los cuatro atributos de los símbolos rituales señalados por Turner (condensación de muchos significados en una forma única, en lo que además destaca la polarización de sentido en un polo ideológico y un polo sensorial; economía de referencia; predominio de cualidad emocional; asociación con regiones de lo inconsciente) pero incluye la necesidad de considerar lo "ominoso o siniestro, anómalo" (unheimlich: "estructura de sentimiento particular en la cual lo más familiar es invadido por lo furtivo, lo clandestino, lo misterioso, lo escondido, lo siniestro o lo secreto" (302)) y "lo familiar" (heimlich), así como un atributo más que es la desproporción de los símbolos (299).

Con todo esto, Díaz insiste en observar el papel de las acciones simbólicas, en particular de los rituales, como una clase de poder, "como dispositivos que instituyen los centros activos del orden social y que producen efectos en todo sistema de poder, o como elementos que pueden propiciar la evolución de las estructuras de poder; en suma, reconocer que los rituales pueden estar conectados de alguna forma con la manera en que el mundo y la figura del mundo están construidos" (147).

$\mathrm{Al}$ ahondar en el mundo de lo ritual recuerda que ya Turner señaló que éstos son transformatorios, mientras que las ceremonias son confirmatorias; ello para observar que los rituales políticos no son "una máscara del poder o un dispositivo que sólo expresa o camuflajea; son en sí mismos una clase de poder y de su consagración, tiene[n] fuerza performativa" (153). Lo anterior le permite definir a los rituales políticos, dice: "son transformatorios; actos de institución, constituyen ellos mismos procesos políticos impregnados de y atravesados por eficacia performativa e investiduras simbólicas; son actos persuasivos de dramaturgia política a la que se someten diversos actores humanos y no humanos" (154).

También complementa a Turner al destacar la importancia de las ceremonias institucionales y de la ritualización. Asimismo, recupera la importancia de la exégesis interna y la externa para dar cuenta de los conocimientos de los nativos, en lo que se hace presente la memoria del símbolo y los efectos retrospectivos de las prácticas simbólicas que transforman el significado inicial de la práctica o de la acción (284).

En esta demasiado apretada síntesis, pareciera que sólo se habla de Turner, pero no es así pues el libro pretende ofrecer una antropología, "disciplina que oscila 
incómoda entre dos polos: la explicación científica y la comprensión humanística: la explicación de la diversidad a partir de la unidad y la deseable "conversación de la humanidad'; la tensión entre distancia y experiencias compartidas" (54); una renovada antropología que esté fuera de la "razón arrogante" (315 y ss.) pagada de sí misma que ha montado las premisas con las que se rigen las formas de comprensión y producción de conocimiento de este vapuleado occidente -así suelen llamarlo - actual. Una nueva antropología que no se siente en el balcón del "ojo de Dios", sino que se sumerja en las profundidades de la fluidez de la vida misma, las tensiones y contradicciones, lo mismo que las estabilidades y permanencias; que será posible en el estudio de los dramas sociales que revelarán "cómo lo general y lo específico, lo cíclico y lo excepcional, lo regular e irregular, lo normal y lo anómalo están interrelacionados en procesos sociales únicos" (102). Una antropología de entretejimientos y urdimbres que dé cuenta de las transiciones desgarradas donde la razón se bifurca. 